\title{
Application of design of experiments and artificial neural networks for stacking sequence optimizations of laminated composite plates
}

\author{
A. Ramanjaneya Reddy ${ }^{1 *}$, B. Sidda Reddy ${ }^{2}$ and K. Vijaya Kumar Reddy ${ }^{3}$ \\ ${ }^{1,2}$ R. G.M. College of Engineering \& Technology, Nandyal, A.P, INDIA \\ ${ }^{3}$ J. N. T. U. H. College of Engineering, Kukatpally, Hyderabad, A.P, INDIA \\ "Corresponding Author: e-mail: markantianjaneya@gmail.com, Tel +91-970186 8913,Fax.+91-08514-275 123
}

\begin{abstract}
This paper discusses the use of Distance based optimal designs in the design of experiments (DOE) and artificial neural networks (ANN) in optimizing the stacking sequence for simply supported laminated composite plate under uniformly distributed load (UDL) for minimizing the deflections and stresses. A number of finite element analyses have been carried out using Distance-based optimal design, for training and testing of the ANN model. The deflections and stresses were found by analyses which were done by finite element analysis software. The ANN model has been developed using multilayer perceptron (MLP) back propagation algorithm. The adequacy of the developed model is verified by coefficient of determination (R). The sensitivity analysis has been performed to study the behavior of the laminated composite plate. The results obtained from the ANN model are compared with the finite element results. For various fibre orientations, deflections and stresses analyses are performed to get the optimal fibre orientations. A verification tests are also performed to prove the effectiveness of the ANN technique after the optimum levels of fibre orientations are determined. The confirmation experimental results show that deflections and stresses are very good agreed with the finite element (FE) results. Consequently, the Distance-based optimal set of laminates and ANN are shown to be effective for optimization of stacking sequence of laminated composite plates.
\end{abstract}

Keywords: DOE, Laminated composite plates, ANN, MLP, Distance- based optimal design, Finite element analysis.

DOI: http://dx.doi.org/10.4314/ijest.v3i6.24

\section{Introduction}

The application of composites is increasingly being used in a large variety of structures including aerospace, marine and civil infrastructure owing to the many advantages they offer: high strength/stiffness for lower weight, superior fatigue response characteristics, facility to vary fibre orientation, material and stacking pattern. At the same time, the fabricated material poses new problems, such as failure due to delamination and pronounced transverse shear effects due to the high ratio of in-plane modulus to transverse shear modulus. Such difficulties can be analyzed to predict the behavior of composite laminates accurately (Kant et al, 1988). Optimum design of fiber composite plates is one of the most interesting and yet intricate problems of structural mechanics. This is due to the increased number of the variables and levels of interrelation as compared to the case of isotropic materials. In order to optimally design such a plate, the number of layers or plies necessary as identified by their angles of fiber orientations must be decided upon, as well as their required thicknesses for a specified load carrying capacity. Laminated composite materials are usually fabricated from unidirectional plies of given thickness and with fibre orientations limited to a small set of angles, eg., $0^{\circ}, 45^{\circ},-45^{\circ}$ and $90^{\circ}$ (Todoroki and Ishikawa, 2004). For designing of such laminates and optimizing the stacking sequence for various strength and stiffness requirements, integer programming and genetic algorithms are popularly used (Haftka, 1992; Richie and Haftka, 1995). Unfortunately for integer programming techniques usually require large computational resources; where as genetic algorithms may not give guaranty to integer valued solutions.

The analysis of plates and shell using the finite element method has been studied by a variety of approaches. Lin and Lee (2004) used the genetic algorithm to optimize the stacking sequence of laminated composite structures. In that, a local search is 
replaced by a regression model to reduce the huge calculation time of genetic algorithm. They found that, genetic algorithm (GA) converged much sooner than a standard GA. Abouhamze and Shakeri (2007) applied weighted summation method to optimize stacking sequence of laminated cylindrical panels with respect to the first natural frequency and critical buckling load. Riche and Haftka (1993) used a genetic algorithm to optimize the stacking sequence of a composite laminate for maximum the buckling load. Shakeri and Gol (2007) is optimized the natural frequency and buckling load using genetic algorithms. In that, they solved a series of optimization problems combining the two objective functions, the Pareto set is generated by optimizing a combination of the two objectives and the best stacking sequence is obtained. Todoroki and Terada (2004) developed the improved Fractal Branch and Bound method for stacking-sequence optimizations of Laminates using D-Optimal designs for maximum buckling load.

A new iteration fractal branch and bound method is proposed to optimize the multiple stacking sequences of a hat-type stiffened panel (Todoroki and Sekishiro, 2007). Al-filfily (2011) used response surface methodology and genetic algorithm to obtain maximum buckling load for laminated composite plate subjected to both mechanical and thermal loads. He used the probabilistic design system analysis module included in the ANSYS program. Todoroki and Ishikawa (2004) applied the $D$-optimal designs in the design of experiments, response surface methodology and genetic algorithm to determine the optimum stacking sequence for maximum buckling loads of a laminated composite cylinder under axial compression load. Choudhary and Tungikar (2011) analyzed the geometrically nonlinear behavior of laminated composite plates using the finite element analysis. They studied the effect of number of layers, effect of degree of orthotropy (both symmetric and anti symmetric) and different fibre orientations on central deflections.Yuarrming et al (2005) carried the optimization of a hat stiff stiffened laminated composite panel of a typical passenger bay of a blended wing body type transport airplane using neural network based response surface method and genetic algorithm to determine the minimum weight. Han et al (2006) performed the post buckling analysis of laminated composite plates when subjected to the combination of in-plane shear, compression and lateral load. They used an Element-based Lagrangian formulation. They concluded that, the combination of various types of loading and lay-up sequences play a major role in determining the nonlinear characteristics.

Farshi and Herasati (2005) designed the composite plate for minimum weight with minimum thickness that can sustain multiple static loadings applied normal to its surface without exhibiting failure of any kind in anyone of its layers, treating that the fibre orientation as discrete variables. They concluded that, the largest value of safety factor would always correspond to the best combination of normalized thicknesses in an assumed stacking order of the ply angles. Van et al (2007) developed locking-free 4-node element, within the framework of the first-order shear deformation theory (FSDT) that is able to work well in highly distorted forms for analysis of laminated composite plates/shells of different shapes. Ngo Nhu Khoa and Tran Ich Thinh (2007) developed a rectangular non-conforming element based on Reddy's higher order shear deformation plate theory to analyze the laminated composite plates. They concluded that, the size of mesh and the convergence of method is involved by thickness ratio (h/a). Civalek (2008) developed a new numerical technique, the discrete singular convolution (DSC) method, for static analysis of thick symmetric cross-ply laminated composite plates based on the first-order shear deformation theory. They concluded that, the deflections response to a uniform load is higher than the response to a sinusoidal load and the deflection and stress values are sensitive to the kernel parameter $r$ and grid numbers. Tahani and Nik (2009) developed an analytical method for bending analysis of laminated composite plates with arbitrary lamination and boundary conditions. Pandya and Kant (1988) considered the higher order displacement model to bring out the effects of neglecting transverse normal stress/strain but at the same time retaining the higher-order in-plane degrees-of-freedom in the formulation. They found that, the results of transverse shear stresses obtained using equilibrium equations and plate constitutive relations are maximum for the sandwich plate rather than the laminated plates.

Aktaş (2011) studied the optimality criteria for central composite, Box-Behnken designs, using D-optimality and distance based optimality to achieve a robust design and compared with the original design approach. Marengo and Todeschini (1992) developed a new algorithm for optimal, distance based, experimental design which does not require any preliminary hypothesis about a regression model and the best set of experiments defined through a fast exchange algorithm. In that, in each cycle, a substitution is selected to provide the maximum increase of the minimum distance between the currently selected experiments. Vukmiroviã et $a l$ and Kuzmanoviã et al $(2005,2011)$ used the two different optimality criteria (information and distance based) for constructing the efficient conjoint experimental design. Todoroki and Sasai (2003) used the D-optimal designs for Stacking sequence optimizations using genetic algorithm with zoomed response surface on lamination parameters for maximizing the buckling load. The Present work is concerned with the optimization of stacking sequence of laminated composite plates using Distance based optimal design of experiments in the design of experiments technique and artificial neural networks. The conformation experiments show that the maximum absolute relative error predicted by ANN and FE results is $4.31 \%$ which is less than $5 \%$. Hence ANN model predicted results are very good agreed with the FE results.

\section{Geometry of the Linear Layered Structural Shell Element}

There are many element types, in ANSYS software, available to model layered composite materials. In our FE analysis, the linear layered structural shell element is used. It is designed to model thin to moderately thick plate and shell structures with a side-to-thickness ratio of roughly 10 or greater. The linear layered structural shell element allows a total of 250 uniform-thickness layers. Alternately, the element allows 125 layers with thicknesses that may vary bilinearly over the area of the layer. It also has an 
option to offset the nodes to the top or bottom surface. The geometry of the linear layered structural shell element is shown in Figure 1.

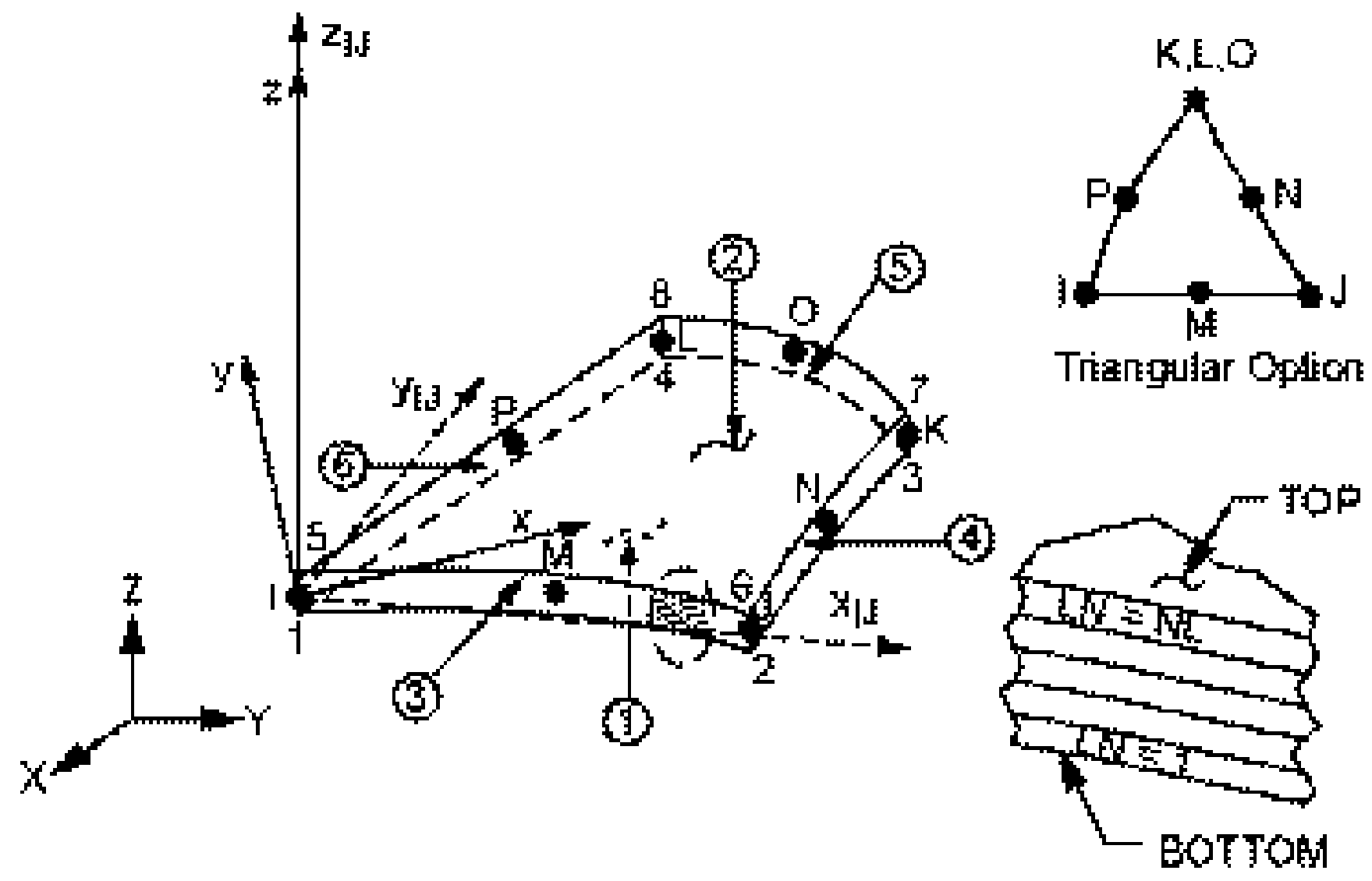

Where

Figure1. Geometry of 8-node element with six degrees of freedom

$x_{I J}=$ Element $\mathrm{x}$-axis if ESYS (Element co-ordinate system) is not supplied.

$\mathrm{x}=$ Element $\mathrm{x}$-axis if ESYS is supplied.

$L N=$ Layer Number

$N L=$ Total Number of Layers

$I, J, K, L, M, N, O, P=$ Nodes

The input includes element geometry, element material properties, boundary conditions and loadings. Briefly, the force-strain and moment-curvature relationships for a linear variation of strain through the thickness of $\mathrm{k}^{\text {th }}$ layer may be defined as in Eq. (1).

$$
\begin{aligned}
& \left\{\frac{N}{M}\right\}=\left[\begin{array}{ll}
A & B \\
B & D
\end{array}\right]\left\{\frac{\varepsilon}{K}\right\}-\left\{\begin{array}{l}
M T \\
B T
\end{array}\right\} \\
& A_{i j}-\sum_{k=1}^{N} \bar{Q}_{i j}^{(k)}\left(z_{k+1}-z_{k}\right) \\
& B_{i j}=\frac{1}{2} \sum_{k=1}^{N} \bar{Q}_{i j}^{(k)}\left(z_{k+1}^{2}-z_{k}^{2}\right) \\
& D_{i j}=\frac{1}{3} \sum_{k=1}^{N} \bar{Q}_{i j}^{(k)}\left(z_{k+1}^{3}-z_{k}^{3}\right)
\end{aligned}
$$

Where $\{\mathrm{MT}\}$ and $\{\mathrm{BT}\}$ are resultant forces and moments for considering thermal effects. The stress output is shown in Figure 2. 


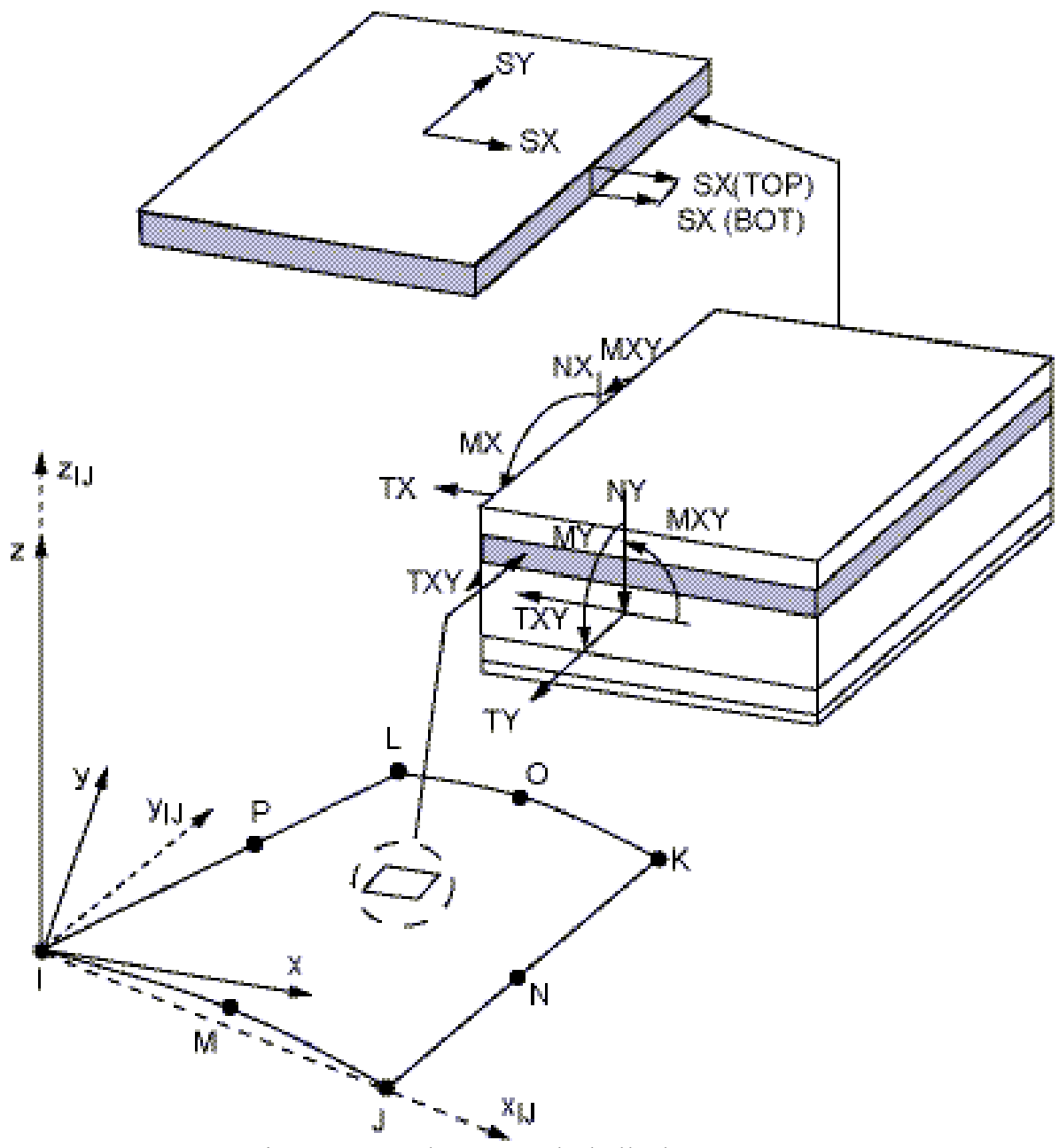

Figure 2. Linear Layered Structural Shell Element Stress Output

Where $x_{I J}=$ Element $\mathrm{x}$-axis if ESYS is not supplied.

$$
x=\text { Element } \mathrm{x} \text {-axis if ESYS is supplied }
$$

\section{Design of Experiments and Artificial neural networks}

\subsection{Design of Experiments}

A Design of Experiment (DOE) is a structured, organized method for determining the relationship between factors affecting a process and the output of that process. Standard DOE arrangements are available for box-like or spherical domains. However, we cannot use such simple geometrical arrangement of points for more complicated design domains. Instead, a Distance based optimal computer-generated DOE is used to select design data points. Distance-based optimality criterion spreads the design points uniformly over the design space. The distance-based method can be used when it is not possible or desirable to select a model in advance. The distance-based method provides one solution for selecting the design points (Meyers and Montgomery, 1995).

\subsection{Artificial neural Networks}

The use of artificial neural networks (ANN) has been well accepted in the areas of telecommunication, signal processing, pattern recognition, prediction, process control and financial analysis. Artificial neural networks which are simplified models of the biological neuron system, is a massively parallel distributing processing system made up of highly interconnected neural computing elements or processing units is called neurons. Neural networks are built by connecting these neurons together by weighted inter connections. Determination of these weights called training is the most significant task. In supervised learning the network is trained to learn a mapping from certain inputs to given outputs. An example of supervised learning is the back propagation method for multilayer perceptron (MLP) networks. Multilayer means the addition of one or more hidden layers in between the input and output layers. In the network each neuron receives total input from all of the neurons in the preceding layer according to the Eq. (2). 
$n t_{j}=\sum_{j=0}^{N} W_{i j} X_{i}$

Where net $t_{j}$ is the total or net input and $\mathrm{N}$ is the number of inputs to the $\mathrm{j}^{\text {th }}$ neuron in the hidden layer. $\mathrm{W}_{\mathrm{ij}}$ is the weight of the connection from the $i^{\text {th }}$ neuron in the forward layer to the $\mathrm{j}^{\text {th }}$ neuron in the hidden layer. A neuron in the network produces its output (Out ${ }_{\mathrm{j}}$ ) by processing the net input through an activation (Transfer) function, such as Tangent hyperbolic function as in Eq. (3).

$$
O u t_{j}=f\left(n e t_{j}\right)=\frac{1-e^{-n e t j}}{1+e^{-n e t j}}
$$

In the training process the algorithm is used to calculate neuronal weights, so that the squared error between the calculated outputs and observed outputs from the training set is minimum and is calculated using Eq. (4).

$$
E=\sum_{i} \sum_{i}\left(d_{i}-y_{i}\right)^{2}
$$

Where $d_{i}$ is the desired response (or target signal), $y_{i}$ are the output units of the network, and the sums run over time and over the output units. When the mean square error is minimized, the power of the error (i.e. the power of the difference between the desired and the actual ANN output) is minimized (Jose Principe et al, 2006).

\section{Stacking sequence optimization using artificial neural networks}

\subsection{Model description}

The physical structure that used in this work is a fibre reinforced composite plate, shown in Figure 3. The length and width of the plate is $250 \mathrm{~mm}$ and thickness of the plate is $25 \mathrm{~mm}$. the ply orientation is treated as a design variable.

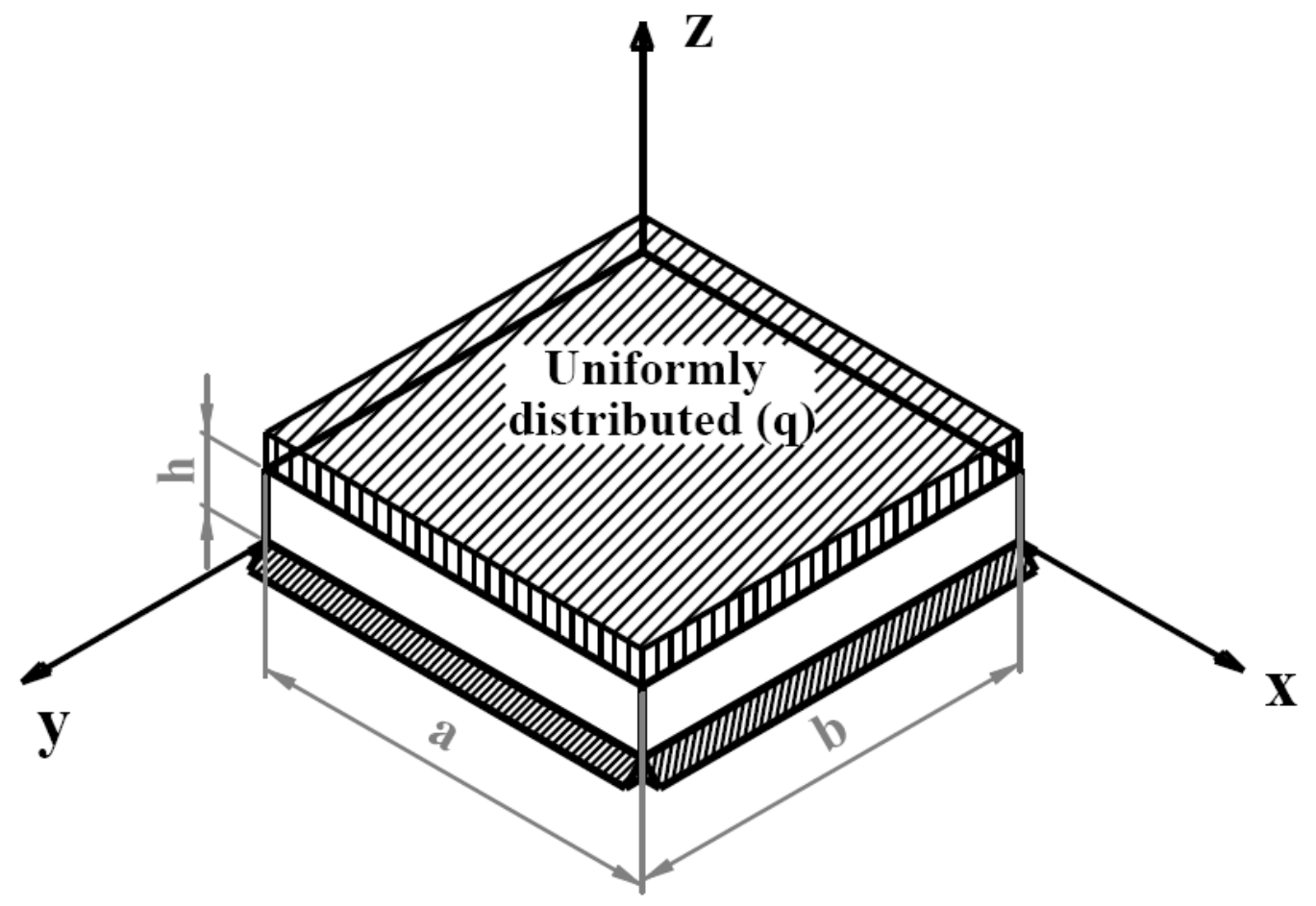

Figure 3. Uniformly loaded simply supported composite plate

\subsection{Finite element model}

A total 120 analyses are performed in this design study, using a finite element model of the plate. The model was developed using linear layered structural shell element in ANSYS 10.0, using 1600 elements. The global x-coordinate is taken along the length of the plate, the global y-coordinate is taken along the width of the plate while the global z-direction is taken out the plate surface. 
There are 40 elements in the axial direction and 40 along the width one (see Figure 3). The plate is analyzed for deflections and stresses under simply supported boundary condition when the plate is subjected to uniformly distributed load.

\subsection{Validation of linear layered structural shell element- case study}

In order to validate the usage of the linear layered structural shell element, a numerical example is solved in static analysis. The boundary condition is simply supported and the geometry and material properties are as follows:

$\mathrm{E}_{1} / \mathrm{E}_{2}=40, \mathrm{G}_{12}=\mathrm{G}_{13}=0.6 \mathrm{E}_{2}, \mathrm{G}_{23}=0.5 \mathrm{E}_{2, v_{12}}=0.25, \mathrm{a} / \mathrm{h}=10, \mathrm{a}=10 . \mathrm{q}=1.0$. The center deflection and stresses are presented here in non-dimensional form using the following:

$$
\bar{w}=w \times \frac{E_{2} h^{3}}{q a^{4}} \times 10^{3}, \bar{\sigma}_{x}=\sigma_{x} \times \frac{h}{a q}, \bar{\sigma}_{y}=\sigma_{y} \times \frac{h}{a q} \text { and } \bar{\tau}_{x y}=\tau_{x y} \times \frac{h}{a q}
$$

Table 1 and Table 2 represent comparisons of results of nondimensional displacement obtained from Reddy (1997) and the ANSYS computer program. The results using a free mesh show an excellent correlation to the results given by Reddy (1997).

Table 1. Nondimensional displacement of composite plates (cross- ply)

\begin{tabular}{lllll}
\hline Mesh & $0 / 90$ & $0 / 90 / 0$ & $0 / 90 / 90 / 0$ & $0 / 90 / 0 / 90$ \\
\hline $2 \times 2$ & 14.222 & 6.8178 & 6.5423 & 6.7662 \\
$4 \times 4$ & 14.478 & - & 6.7402 & 6.9897 \\
$10 \times 10$ & 14.488 & 6.9904 & - & 6.9965 \\
$20 \times 20$ & 14.488 & 6.9905 & 6.7459 & 6.9966 \\
$40 \times 40$ & 14.475 & 6.9857 & 6.7405 & 6.9904 \\
FSDT (Reddy) & 14.069 & 6.919 & 6.682 & 6.9260 \\
\hline Difference (\%) & 2.8857 & 0.9640 & 0.8754 & 0.929 \\
\hline
\end{tabular}

Table 2. Nondimensional displacement of composite plates $(\theta /-\theta / \theta /-\theta)$

\begin{tabular}{lll}
\hline Mesh & 5 & 15 \\
\hline $2 \times 2$ & 6.7716 & 6.3811 \\
$4 \times 4$ & - & 6.6625 \\
$10 \times 10$ & 6.9652 & - \\
$20 \times 20$ & - & 6.6668 \\
$40 \times 40$ & 6.9623 & 6.6631 \\
$F S D T$ (Reddy) & 6.741 & 6.086 \\
\hline Difference (\%) & 3.2828 & 9.4824 \\
\hline
\end{tabular}

\subsection{Experimental Details}

In the present study, the Distance- based optimality design has been implemented to select a feasible set of laminates from among all feasible laminates. Let us consider the case of a 16-ply laminate. The total number of entire feasible laminates is $3 \times 4 \times 4 \times 4 \times 4 \times 4 \times 4 \times 4=49152$, because we consider only a symmetric laminate and we adopt 3 levels $\left(0^{\circ}, 45^{\circ}\right.$ and $\left.90^{\circ}\right)$ for the first ply orientation and the remaining plies with 4 levels $\left(-45^{\circ}, 0^{\circ}, 45^{\circ}\right.$ and $\left.90^{\circ}\right)$. We can select feasible laminates from the set of feasible laminates using distance based optimal. In this study, the total 120 feasible laminates were selected for training and testing of the artificial neural network model. The selected Distance- based optimal set of laminates design was performed using MINITAB 14 software and is presented in Table 3. The material properties used through out this study are shown in Table 4 (Baker et al., 2004).

\subsection{Development of ANN model}

One of the key issues when designing a particular neural network is to calculate proper weights for neuronal activities. These are obtained from the training process applied to the given neural network. To that end, a training sample is provided, i.e. a sample of observations consisting of inputs and their respective outputs. The observations are fed to the network. In the training process the algorithm is used to calculate neuronal weights, so that the squared error between the calculated outputs and observed outputs from the training set is minimized (Principe et al, 2006).

4.5.1Designing of the Neural Network Architecture

The optimal neural network architecture 8-30-4 was used in this study. It was designed using NeuroSolutions 4.0 software. The network consists of one input, one hidden and one out put layer. The input layer has 8 neurons, hidden layer has thirty neurons and output layer has four neurons respectively. Since deflection, stresses (Normal stress in X-direction (Sx), Normal stress in Y- 
direction (Sy), shear stress in XY plane (Sxy)) prediction in terms of ply orientation was the main interest in this research, neurons in the input layer corresponding to the number of plies the output layer corresponds to deflection and stresses.

4.5.2. Generation of Train and Test Data

To calculate the connection weights, a set of desired network output values are needed. Desired output values are called the training data set. The training data set in this study was selected based on Distance-based optimal design in the design of experiments. In this study, 110 data sets were used for training and 10 data sets were used for testing the network and are given in Table 3.

Table 3. Selected Distance- based optimal set of laminates

\begin{tabular}{|c|c|c|c|}
\hline $\begin{array}{ll}\text { S.No. } & \text { stacking sequence } \\
\end{array}$ & S.No. Stacking sequence & S.No & Stacking sequence \\
\hline \multicolumn{4}{|l|}{ Training Data } \\
\hline 1. $[90 / 90 / 90 / 90 / 90 / 90 / 90 / 90]_{\mathrm{s}}$ & 45. $[0 /-45 /-45 /-45 / 90 / 90 /-45 /-45] \mathrm{s}$ & 89. & {$[0 / 90 / 0 / 90 / 90 / 90 / 0 / 0] \mathrm{s}$} \\
\hline 2. $[0 /-45 /-45 /-45 /-45 /-45 /-45 /-45]_{\mathrm{s}}$ & 46. $[0 /-45 /-45 / 90 / 45 / 90 /-45 / 45] \mathrm{s}$ & 90. & {$[0 / 90 / 90 / 90 / 90 / 90 / 45 /-45] \mathrm{s}$} \\
\hline 3. $[0 /-45 /-45 /-45 / 45 / 90 / 90 / 90]_{\mathrm{s}}$ & 47. $[0 /-45 / 90 /-45 /-45 / 90 /-45 /-45] \mathrm{s}$ & 91. & {$[0 / 90 / 90 / 90 / 90 / 90 / 90 / 90] \mathrm{s}$} \\
\hline 4. $[0 / 45 / 90 /-45 / 90 / 90 /-45 /-45]_{\mathrm{s}}$ & 48. $[0 /-45 / 90 / 90 /-45 /-45 /-45 /-45] \mathrm{s}$ & 92. & {$[45 / 0 / 0 /-45 / 0 / 45 / 0 /-45] \mathrm{s}$} \\
\hline 5. $[0 / 90 /-45 / 90 /-45 / 90 /-45 / 45]_{\mathrm{s}}$ & 49. $[0 / 45 / 0 / 45 /-45 / 0 /-45 /-45] \mathrm{s}$ & 93. & {$[45 /-45 / 0 / 0 / 0 / 0 / 0 / 0] \mathrm{s}$} \\
\hline 6. $[0 / 90 / 90 /-45 /-45 /-45 / 45 / 90]_{\mathrm{s}}$ & 50. $[0 / 90 /-45 /-45 /-45 /-45 /-45 / 90] \mathrm{s}$ & 94. & {$[45 /-45 / 0 / 0 / 0 / 90 / 90 / 90] \mathrm{s}$} \\
\hline 7. $[90 /-45 /-45 / 90 / 90 / 90 / 0 /-45]_{\mathrm{s}}$ & 51. $[0 / 90 /-45 / 90 / 90 /-45 /-45 /-45] \mathrm{s}$ & 95. & {$[45 /-45 / 45 /-45 / 0 / 0 / 0 / 0] \mathrm{s}$} \\
\hline 8. $[90 /-45 / 90 /-45 / 90 /-45 / 90 / 0]_{\mathrm{s}}$ & 52. $[90 /-45 /-45 / 45 / 90 / 0 /-45 / 90] \mathrm{s}$ & 96. & {$[45 /-45 / 45 /-45 / 45 /-45 / 0 / 0] \mathrm{s}$} \\
\hline 9. $[90 / 90 / 90 / 90 / 0 /-45 /-45 /-45]_{\mathrm{s}}$ & 53. $[90 /-45 / 90 /-45 / 90 / 45 /-45 / 45] \mathrm{s}$ & 97. & {$[45 /-45 / 45 /-45 / 45 /-45 / 90 / 90] \mathrm{s}$} \\
\hline 10. $[0 /-45 / 90 / 45 / 90 / 90 / 45 / 45]_{\mathrm{s}}$ & 54. $[90 /-45 / 90 / 45 / 45 / 90 /-45 /-45] \mathrm{s}$ & 98. & {$[45 /-45 / 45 /-45 / 90 / 90 / 90 / 90] \mathrm{s}$} \\
\hline 11. $[0 / 45 /-45 / 90 / 90 / 45 / 45 / 90]_{\mathrm{s}}$ & 55. $[90 /-45 / 90 / 90 /-45 /-45 / 90 / 45] \mathrm{s}$ & 99. & {$[45 /-45 / 90 / 90 / 90 / 0 / 0 / 0] \mathrm{s}$} \\
\hline 12. $[0 / 45 / 90 / 90 / 45 /-45 / 90 / 45]_{\mathrm{s}}$ & 56. $[90 /-45 / 90 / 90 /-45 / 90 / 90 / 90] \mathrm{s}$ & 100. & {$[45 /-45 / 90 / 90 / 90 / 90 / 90 / 90] \mathrm{s}$} \\
\hline 13. $[90 /-45 / 0 /-45 / 0 /-45 / 0 / 90]_{\mathrm{s}}$ & 57. $[90 / 90 /-45 /-45 / 90 / 45 / 45 /-45] \mathrm{s}$ & 101. & {$[90 / 0 / 0 / 0 / 0 / 0 / 0 / 0] \mathrm{s}$} \\
\hline 14. $[90 /-45 / 0 / 90 /-45 / 0 /-45 / 0]_{\mathrm{s}}$ & 58. $[90 / 90 / 45 / 90 /-45 / 90 /-45 /-45] \mathrm{s}$ & 102. & {$[90 / 45 /-45 / 45 /-45 / 0 / 0 / 0] \mathrm{s}$} \\
\hline 15. $[90 / 0 /-45 /-45 / 0 / 90 /-45 / 0]_{\mathrm{s}}$ & 59. $[90 / 90 / 90 /-45 / 90 / 90 /-45 / 90] \mathrm{s}$ & 103. & {$[90 / 45 /-45 / 90 / 45 / 90 /-45 / 90] \mathrm{s}$} \\
\hline 16. $[90 / 0 / 0 / 0 / 90 /-45 /-45 /-45]_{\mathrm{s}}$ & 60. $[0 /-45 /-45 / 45 /-45 / 45 / 90 / 45] \mathrm{s}$ & 104. & {$[90 / 90 / 0 / 0 / 0 / 0 / 0 / 0] \mathrm{s}$} \\
\hline 17. $[90 / 0 / 90 /-45 /-45 / 0 / 0 /-45]_{\mathrm{s}}$ & 61. $[0 /-45 / 0 /-45 / 90 /-45 /-45 / 90] \mathrm{s}$ & 105. & {$[90 / 90 / 0 / 0 / 0 / 0 / 45 /-45] \mathrm{s}$} \\
\hline 18. $[90 / 90 /-45 / 0 /-45 /-45 / 0 / 0]_{\mathrm{s}}$ & 62. $[0 /-45 / 45 /-45 / 90 /-45 / 90 / 90] \mathrm{s}$ & 106. & {$[90 / 90 / 45 /-45 / 45 /-45 / 45 /-45] \mathrm{s}$} \\
\hline 19. $[0 /-45 /-45 /-45 / 90 /-45 / 45 / 0]_{\mathrm{s}}$ & 63. $[0 / 0 /-45 /-45 /-45 / 90 / 90 /-45] \mathrm{s}$ & 107. & {$[90 / 90 / 90 / 90 / 0 / 0 / 0 / 0] \mathrm{s}$} \\
\hline 20. $[0 /-45 /-45 / 0 /-45 / 45 /-45 / 90]_{\mathrm{s}}$ & 64. $[0 / 90 /-45 /-45 / 0 / 90 /-45 / 90] \mathrm{s}$ & 108. & {$[90 / 90 / 90 / 90 / 45 /-45 / 45 /-45] \mathrm{s}$} \\
\hline 21. $[0 /-45 / 90 / 45 /-45 /-45 / 0 / 90]_{\mathrm{s}}$ & 65. $[0 / 90 / 90 / 45 /-45 /-45 /-45 / 45] \mathrm{s}$ & 109. & {$[90 / 90 / 90 / 90 / 90 / 90 / 0 / 0] \mathrm{s}$} \\
\hline 22. $[0 / 0 / 90 / 90 /-45 / 90 /-45 / 0]_{\mathrm{s}}$ & 66. $[90 /-45 /-45 /-45 /-45 / 45 / 90 / 90] \mathrm{s}$ & 110. & {$[90 / 90 / 90 / 90 / 90 / 90 / 45 /-45] \mathrm{s}$} \\
\hline 23. $[0 / 0 / 90 / 90 / 90 / 0 /-45 /-45]_{\mathrm{s}}$ & 67. $[90 / 45 / 90 /-45 /-45 /-45 /-45 / 90] \mathrm{s}$ & & \\
\hline 24. $[0 / 45 /-45 /-45 /-45 / 0 / 90 / 90]_{\mathrm{s}}$ & 68. $[90 / 90 / 45 / 90 / 90 /-45 / 90 /-45] \mathrm{s}$ & Test & data \\
\hline 25. $[0 / 45 /-45 / 90 /-45 / 0 / 90 /-45]_{\mathrm{s}}$ & 69. $[90 / 90 / 90 / 90 / 90 / 45 /-45 / 0] \mathrm{s}$ & & \\
\hline 26. $[0 / 45 /-45 / 90 / 0 /-45 /-45 / 90]_{\mathrm{s}}$ & 70. $[0 /-45 /-45 / 90 / 45 /-45 / 45 / 90] \mathrm{s}$ & & {$[0 /-45 / 45 / 90 / 90 /-45 /-45 / 90] \mathrm{s}$} \\
\hline 27. $[0 / 90 /-45 /-45 / 45 / 0 /-45 /-45]_{\mathrm{s}}$ & 71. $[0 /-45 / 0 /-45 / 0 / 45 / 0 / 0] \mathrm{s}$ & 112. & {$[0 /-45 / 90 / 90 /-45 / 45 / 90 /-45] \mathrm{s}$} \\
\hline 28. $[0 / 90 / 45 /-45 /-45 / 90 /-45 / 0]_{\mathrm{s}}$ & 72. $[0 /-45 / 0 / 90 / 45 / 90 / 90 / 0] \mathrm{s}$ & 113. & {$[90 /-45 /-45 / 0 / 0 / 0 / 90 /-45] \mathrm{s}$} \\
\hline 29. $[45 / 90 / 45 /-45 / 0 /-45 / 90 /-45]_{\mathrm{s}}$ & 73. $[0 /-45 / 45 / 90 / 0 / 45 / 45 / 90] \mathrm{s}$ & 114. & {$[0 /-45 /-45 / 90 / 45 /-45 / 0 /-45] \mathrm{s}$} \\
\hline 30. $[90 /-45 /-45 / 90 / 0 / 90 / 45 / 90]_{\mathrm{s}}$ & 74. $[0 / 45 /-45 /-45 /-45 /-45 / 45 /-45] \mathrm{s}$ & 115. & {$[0 /-45 / 90 /-45 / 45 /-45 /-45 / 0] \mathrm{s}$} \\
\hline 31. $[90 /-45 / 0 / 45 / 90 /-45 / 90 / 90]_{\mathrm{s}}$ & 75. $[0 / 45 /-45 / 90 / 45 / 90 /-45 /-45] \mathrm{s}$ & 116. & {$[90 /-45 / 45 /-45 / 90 / 90 / 45 /-45] \mathrm{s}$} \\
\hline 32. $[90 /-45 / 45 / 90 / 90 / 0 / 90 /-45]_{\mathrm{s}}$ & 76. $[0 / 90 / 90 / 0 / 0 / 45 / 45 / 0] \mathrm{s}$ & 117. & {$[90 / 90 /-45 / 90 / 45 / 45 / 90 / 0] \mathrm{s}$} \\
\hline 33. $[90 /-45 / 90 /-45 / 0 / 45 / 90 / 90]_{s}$ & 77. $[90 /-45 / 45 /-45 /-45 / 90 / 45 / 0] \mathrm{s}$ & 118. & {$[90 / 0 /-45 / 0 / 90 / 90 / 45 / 45] \mathrm{s}$} \\
\hline 34. $[90 / 0 / 45 / 90 / 90 / 90 /-45 / 90]_{\mathrm{s}}$ & 78. $[90 /-45 / 45 / 90 / 90 / 90 / 90 / 90] \mathrm{s}$ & 119. & {$[90 / 45 / 45 / 0 /-45 / 0 / 90 / 45] \mathrm{s}$} \\
\hline 35. $[90 / 45 / 90 /-45 / 90 /-45 / 0 / 90]_{\mathrm{s}}$ & 79. $[45 /-45 / 45 /-45 / 45 /-45 / 45 /-45] \mathrm{s}$ & 120. & {$[0 / 90 /-45 / 0 / 0 / 45 / 45 / 0] \mathrm{s}$} \\
\hline 36. $[90 / 90 /-45 / 0 / 0 / 90 / 45 / 90]_{\mathrm{s}}$ & 80. $[0 / 0 / 0 / 0 / 0 / 0 / 0 / 0] \mathrm{s}$ & & \\
\hline 37. $[90 / 90 /-45 / 45 / 90 / 90 /-45 / 0] \mathrm{s}$ & 81. $[0 / 0 / 0 / 0 / 0 / 0 / 45 /-45] \mathrm{s}$ & & \\
\hline 38. $[90 / 90 / 0 / 90 / 90 /-45 / 0 / 45] \mathrm{s}$ & 82. $[0 / 0 / 0 / 0 / 0 / 90 / 90 / 90] \mathrm{s}$ & & \\
\hline 39. $[90 / 90 / 45 / 90 /-45 / 0 / 0 / 90] \mathrm{s}$ & 83. $[0 / 0 / 0 / 0 / 45 /-45 / 45 /-45] \mathrm{s}$ & & \\
\hline 40. $[0 / 90 / 90 /-45 / 0 /-45 /-45 /-45] \mathrm{s}$ & 84. $[0 / 0 / 0 / 0 / 90 / 90 / 90 / 90] \mathrm{s}$ & & \\
\hline 41. $[45 / 90 /-45 / 0 / 90 /-45 / 90 / 90] \mathrm{s}$ & 85. $[0 / 0 / 45 /-45 / 45 /-45 / 45 /-45] \mathrm{s}$ & & \\
\hline 42. $[45 / 90 / 90 / 90 /-45 / 0 / 90 /-45] \mathrm{s}$ & 86. $[0 / 0 / 90 / 90 / 45 /-45 / 45 /-45] \mathrm{s}$ & & \\
\hline 43. $[90 / 90 / 90 /-45 /-45 / 90 / 45 / 90] \mathrm{s}$ & 87. $[0 / 0 / 90 / 90 / 90 / 90 / 90 / 90] \mathrm{s}$ & & \\
\hline 44. $[90 / 90 / 90 / 0 / 90 / 45 / 45 /-45] \mathrm{s}$ & 88. $[0 / 45 /-45 / 45 /-45 / 90 / 90 / 90] \mathrm{s}$ & & \\
\hline
\end{tabular}


Table 4. Material properties (Boron/epoxy)

\begin{tabular}{lcccccccc}
\hline$E_{1}(\mathrm{GPa})$ & $E_{2}(\mathrm{GPa})$ & $E_{3}(\mathrm{GPa})$ & $G_{12}(\mathrm{GPa})$ & $G_{23}(\mathrm{GPa})$ & $G_{13}(\mathrm{GPa})$ & $v_{12}$ & $v_{23}$ & $v_{13}$ \\
\hline 210 & 19 & 19 & 4.8 & 4.8 & 4.8 & 0.25 & 0.25 & 0.25 \\
\hline
\end{tabular}

\subsubsection{Neural network training}

For calculation of weight variables, often referred to as network training, the weights are given quasi-random, intelligently chosen initial values. They are then iteratively updated until convergence to the certain values using the gradient descent method. Gradient descent method updates weights so as to minimize the mean square error (MSE) between the network prediction and training data set as in Eq. (5) and (6).

$$
\begin{aligned}
& W_{i j}{ }^{\text {new }}=W_{i j}{ }^{\text {old }}+\Delta W_{i j} \\
& \Delta W_{i j}=-\eta \sum_{t=1}^{k} \alpha^{k-t} \frac{\partial E}{\partial W_{i j}}{ }_{\text {out }}
\end{aligned}
$$

Where $E$ is the MSE and out ${ }_{j}$ is the $\mathrm{j}^{\text {th }}$ neuron output. $\eta$ is the learning rate [step size, momentum] parameter controlling the stability and rate of convergence of the network.. The learning rate [step size 1.0, momentum 0.7] selected and the training process takes place on a Intel(R) Atom ${ }^{\mathrm{TM}}$ processor PC for 65,000 training iterations.. The minimum mean square error is calculated for training data is 0.0000201305 . Figure 4 depicts the convergence of minimum MSE with epochs. The comparison between ANN model output and experimental output for training data sets is shown in Figure 5. Figure 5 showing that, the predicted values using ANN is very good correlation and representation with the experimental results. The experimental outputs are resulted from the FE model using ANSYS.

In order to judge the ability and efficiency of the ANN model to predict the deflections and stress values, percentage deviation $(\varnothing)$ and the average percentage deviation $(\bar{\varnothing})$ were used and calculated as in Eq. (7) and (8)

$$
\varnothing_{i}=\frac{\mid \text { Experimental }- \text { Predicted } \mid}{\text { Experimental }} \times 100 \%
$$

Where $\varnothing_{\mathrm{i}}=$ percentage deviation of single sample data

$$
\bar{\varnothing}=\frac{\sum_{i=1}^{n} \varnothing_{i}}{n}
$$

Where $\bar{\varnothing}=$ average percentage deviation of all sample data and $\mathrm{n}=$ size of the sample data. The average percentage deviation for deflection and stresses (Sx, Sy and Sxy) of training data calculated as $0.028875 \%, 1.587178 \%, 2.119705 \%$ and $3.018923 \%$ respectively.

\subsubsection{Neural network testing}

The ANN predicted results are in very good agreement with experimental results and the network can be used for testing. Hence the testing data sets are applied for the network, which were never used in the training process. The results predicted by the network were compared with the experimental measured values. The average percentage deviation for deflection and stresses $(S x$, Sy and $S x y$ ) of test data was found to be $6.132743 \%, 1.3096766 \%, 0.0945797 \%$ and $5.7492823 \%$ respectively.

4.5.6. Regression Analysis

To have more precise investigation into the model, a regression analysis of ANN predicted and experimental measured values were performed and is shown in Figure 6. The adequacy of the developed model is verified by using coefficient of determination $\left(R^{2}\right) .0 \leq R^{2} \leq 1$. The $\mathrm{R}^{2}$ is the variability in the data accounted for by the model in percentage (Montgomery, 2001). 


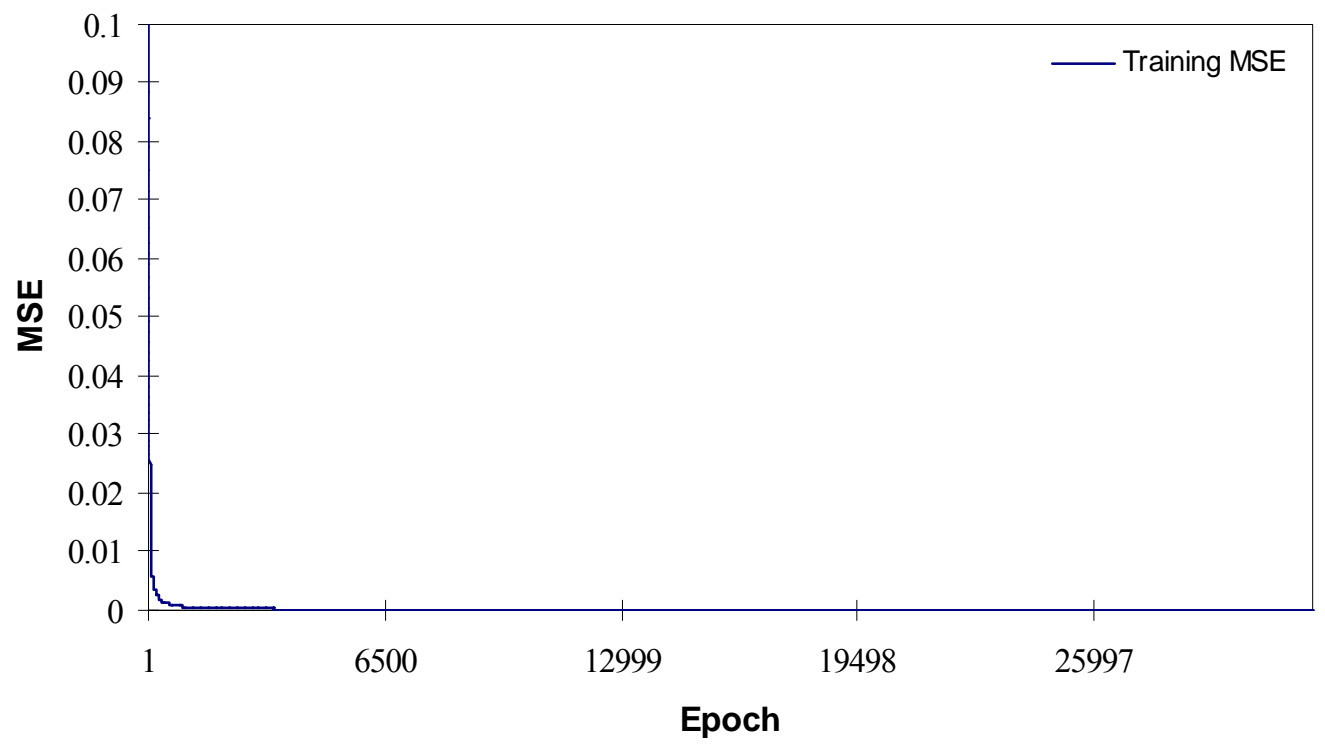

Figure 4. Training MSE

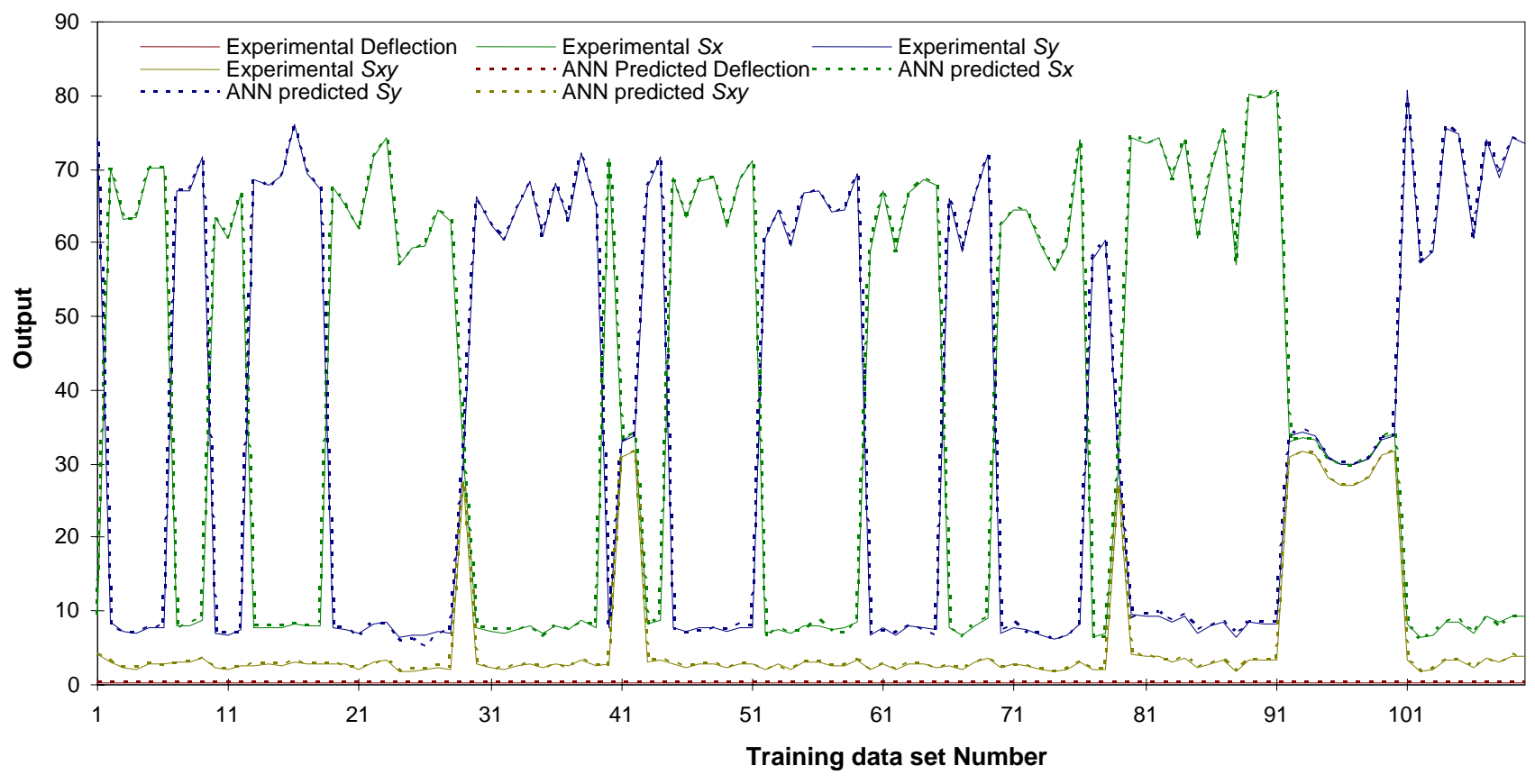

Figure 5. Desired Output and actual network 

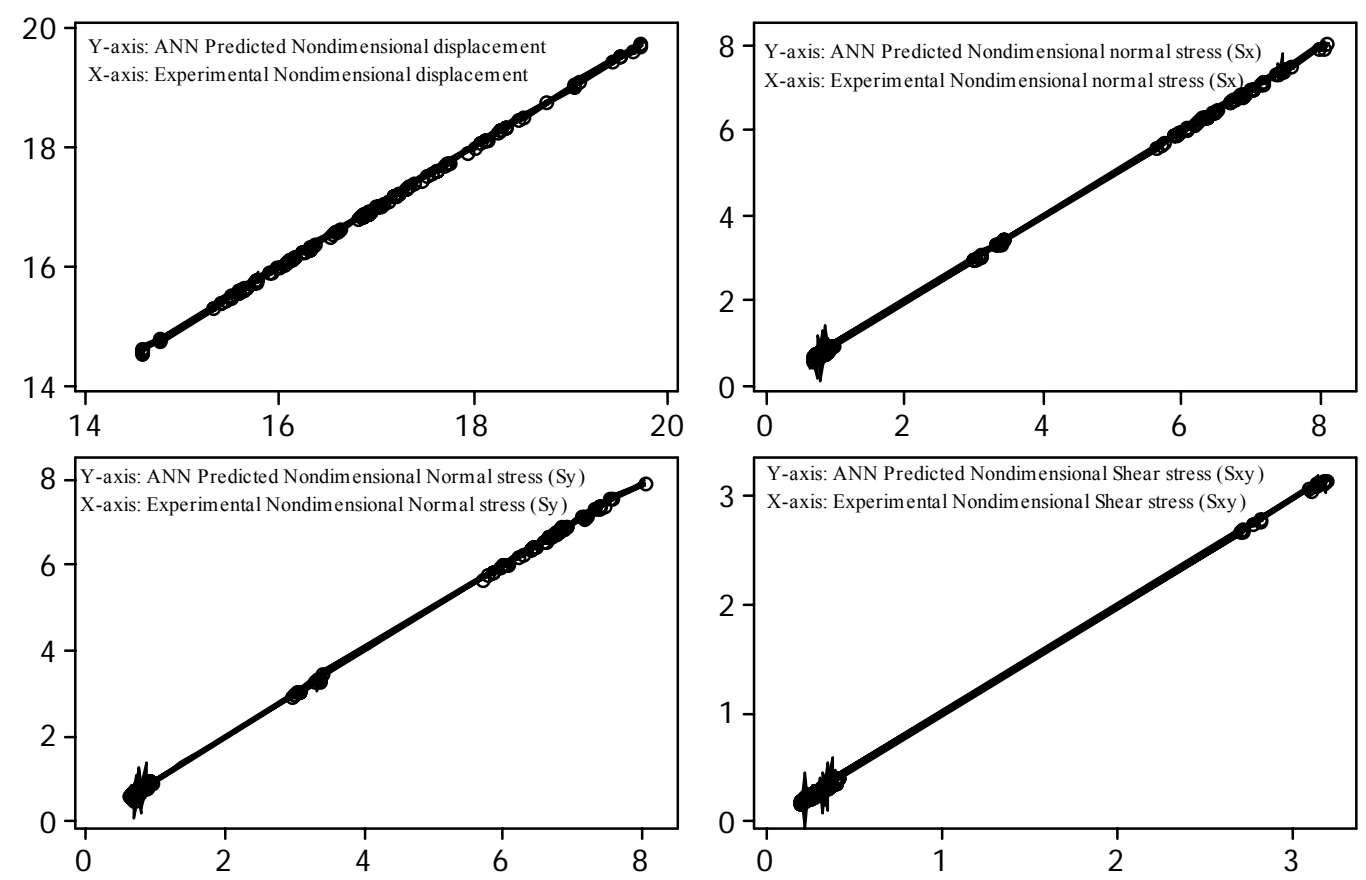

Figure 6. ANN Predicted outputs Vs Experimental measured outputs

The regression coefficients are calculated to estimate the correlation between the ANN predicted values by the ANN model and the experimental measured values resulted from finite element tests. The regression coefficients are calculated by using Eq. (9).

$$
R^{2}=1-\left[\frac{\sum_{j}\left(t_{j}-o_{j}\right)^{2}}{\sum_{j}\left(o_{j}\right)^{2}}\right]
$$

Where $\mathrm{t}_{\mathrm{j}}=$ targets or experimental values or measured values

$\mathrm{o}_{\mathrm{j}}=$ outputs or ANN predicted values.

There is a high correlation between the ANN predicted values by the ANN model and the experimental measured values resulted from finite element analyses .The correlation coefficients for deflections and stresses are 0.999975785, 0.999975785, $0.999959755,0.999929404$ and 0.999909954 respectively, which shows there is a strong correlation in modeling deflections and stresses. From Fig 5, it is very difficult to distinguish the best linear fit line from the perfect line, because the fit is so good. The sensitivity test was performed to study the variation of deflections and stresses with fibre orientation angles and is shown through Figures 7(a)-(d). From Figure 7(a) it is observed that, the deflection is decreases as the fibre orientation angle increases. But only in layer5 and layer 7, the deflection increases. From Figure 7(b)-(d) it is seen that, normal stress in x-direction increases as the fibre orientation angle increases, but in top and bottom layers decreases. The normal stress in y-direction decreases with the increase of fibre orientation angles, where as in layer1, layer2 and layer 7 increases. The transverse shear stress is found to increase with increase in fibre orientation angle but in top, bottom and in layer 3 decreases for side to thickness ratio $(\mathrm{a} / \mathrm{h})=10$. 


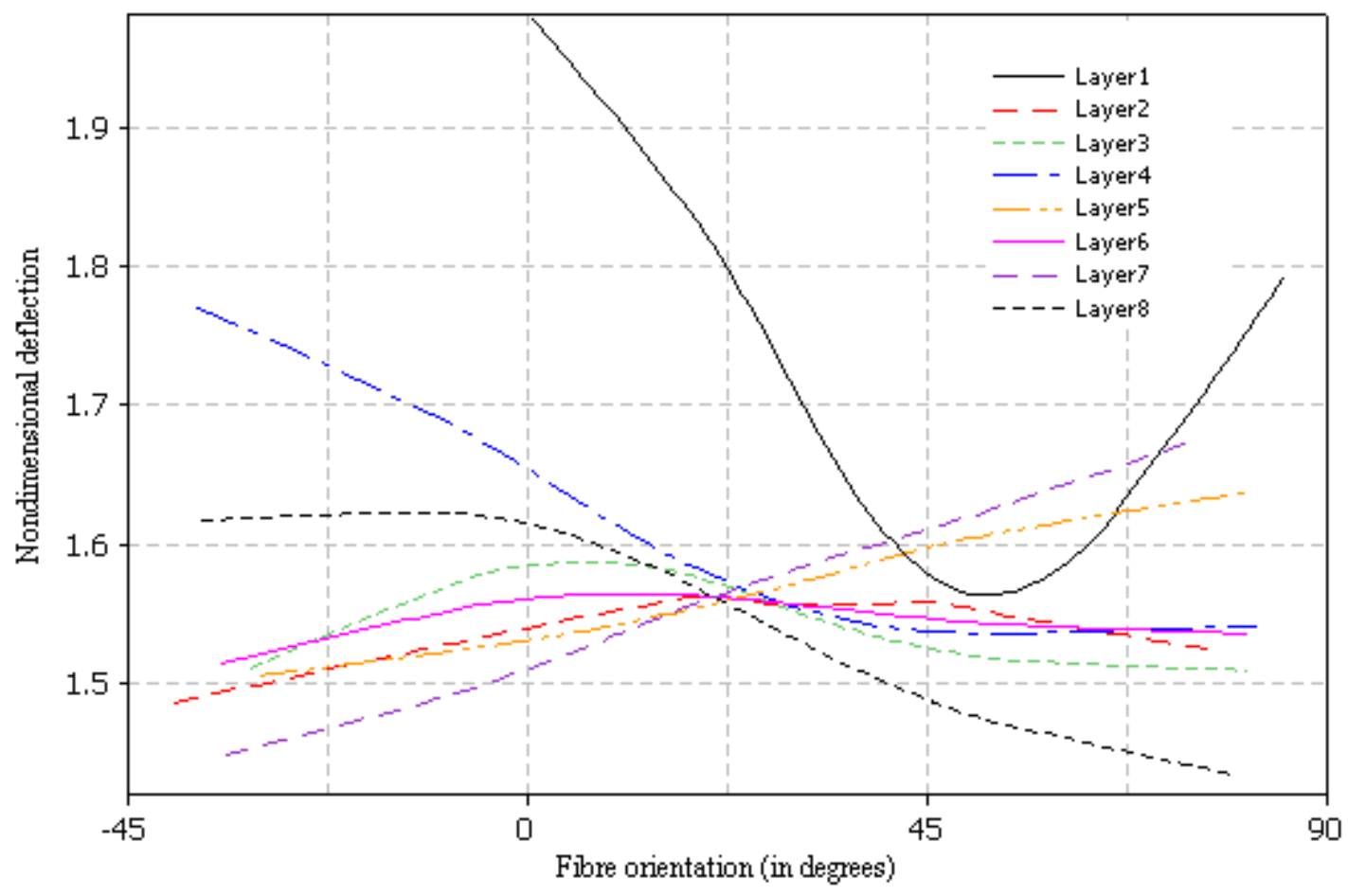

Figure 7 (a). Nondimensional deflection for varied fibre Orientation angles

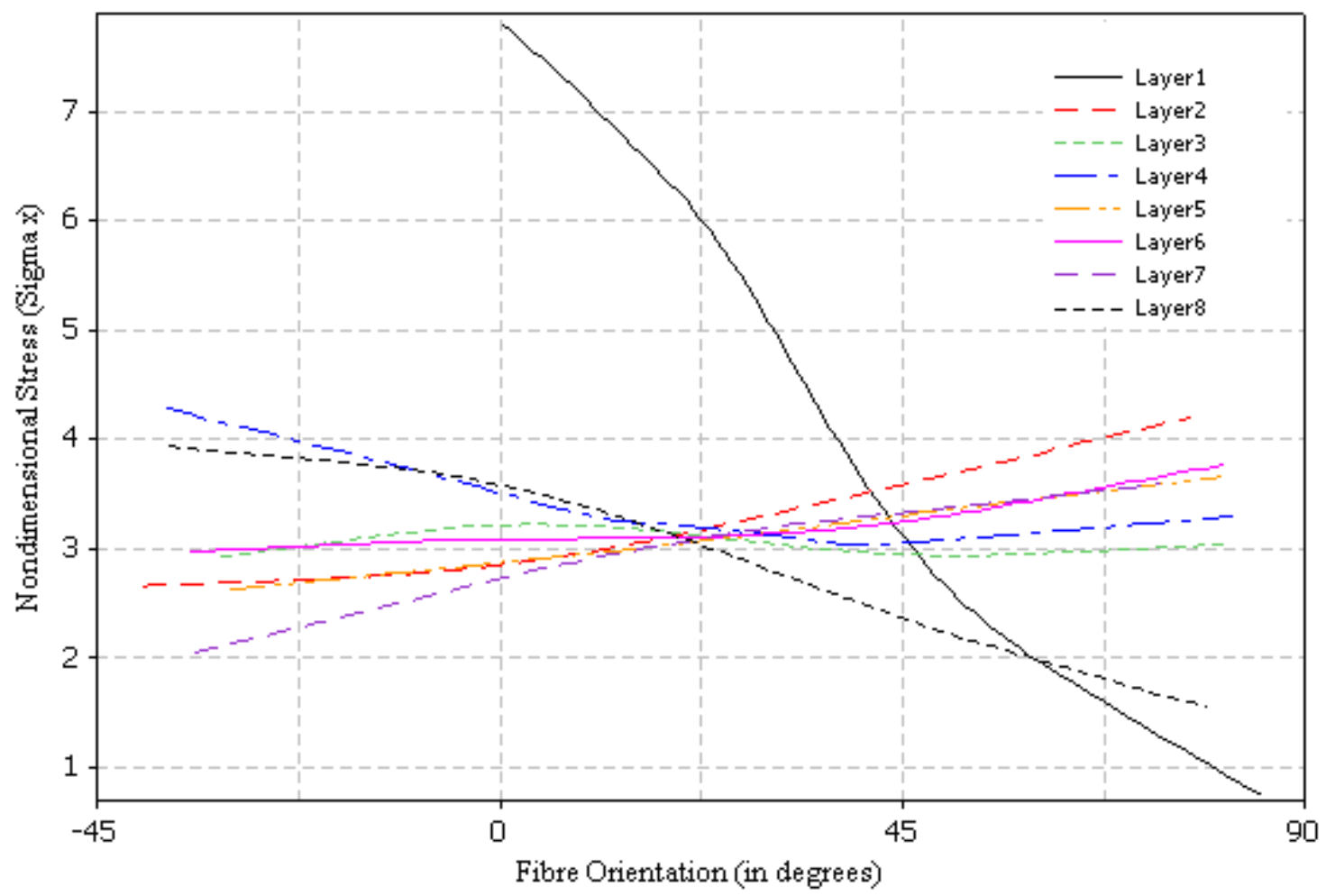

Figure 7 (b). Nondimensional stress $\left(S_{x}\right)$ for Varied fire Orientation 


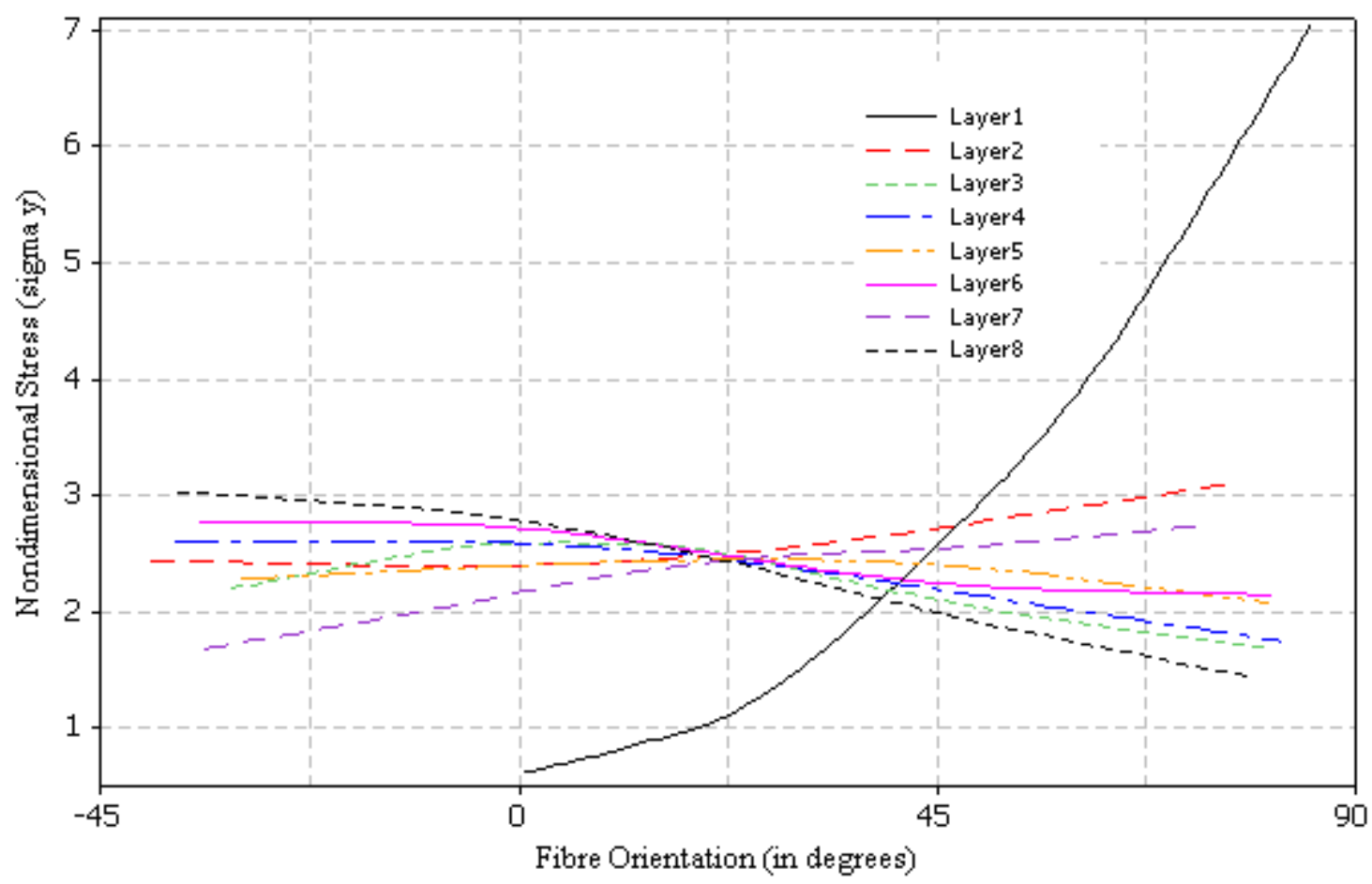

Figure 7 (c). Nondimensional stress $\left(S_{y}\right)$ for Varied fire Orientation

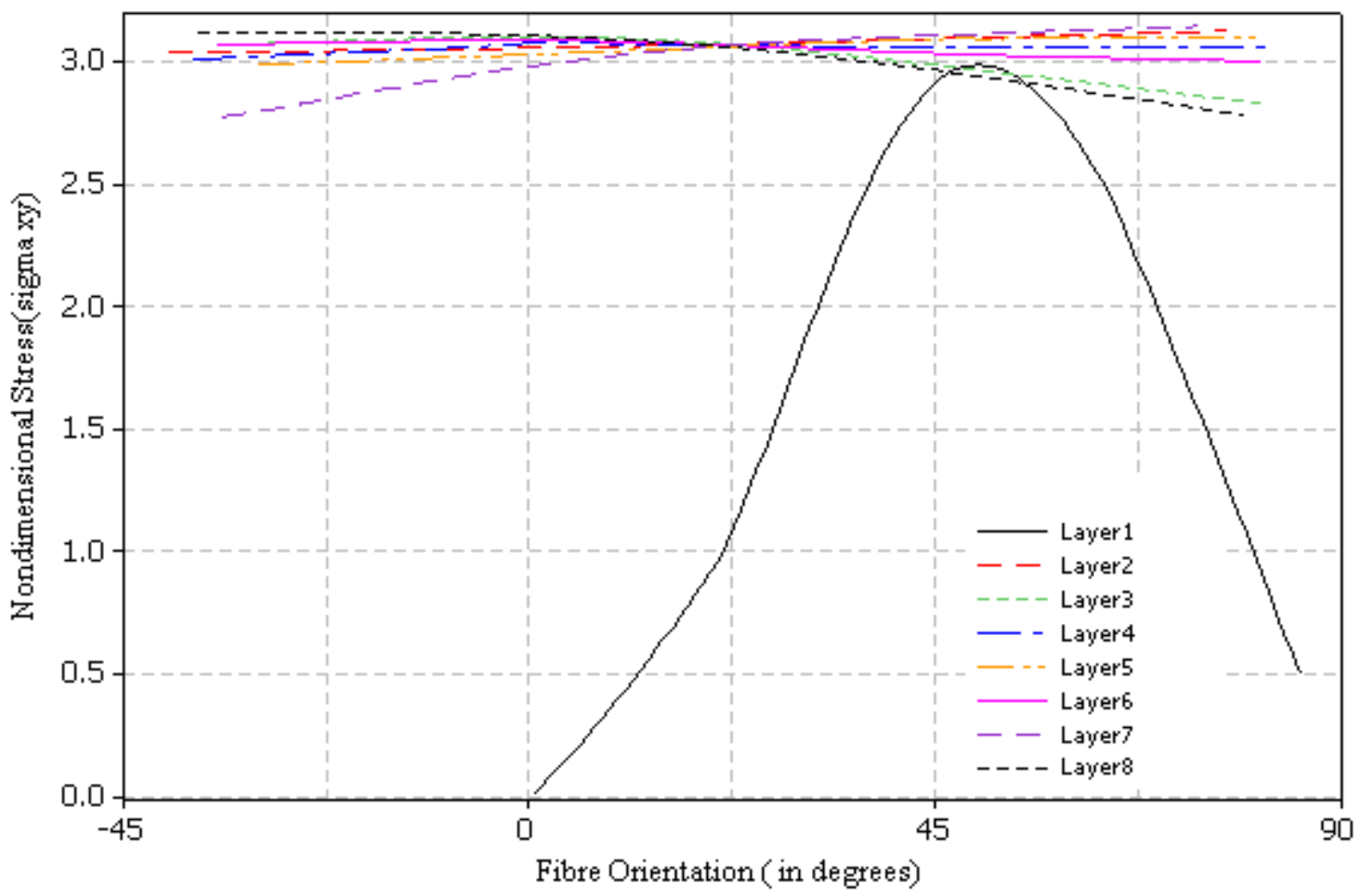

Figure 7 (d). Nondimensional stress $\left(S_{x y}\right)$ for Varied fire Orientation

\subsubsection{Optimization of ply orientation by $A N N$}

The developed ANN architecture is used to provide deflections and stresses. A total 49152 set of laminates is fed to the optimally designed neural network for predicting the deflections and stresses. The optimal stacking sequence corresponds to the minimum deflection and stresses are given in Table 5. A verification tests are also performed to prove the effectiveness of the ANN technique after the optimum levels of fibre orientations are determined. The FE results are compared with the ANN results and 
maximum percentage error is obtained as $4.31 \%$. The nondimensional results predicted from ANN correlates very well with that of from finite element (FE) analyses.

Table5. Optimal stacking sequence obtained by ANN

\begin{tabular}{llccc}
\hline Parameter & Optimal stacking sequence & Nondimensional FE Output & Nondimensional ANN Output & \%Error \\
\hline Deflections: & {$[45 /-45 / 45 /-45 /-45 / 90 / 45 / 0]_{\mathrm{s}}$} & 14.56464 & 14.39728 & 1.149 \\
Stress $\left(\mathrm{S}_{\mathrm{x}}\right):$ & {$[90 / 45 /-45 /-45 /-45 / 45 /-45 /-45]_{\mathrm{s}}$} & 0.64264 & 0.62666 & 2.486 \\
Stress $\left(\mathrm{S}_{\mathrm{y}}\right):$ & {$[0 / 45 /-45 /-45 /-45 /-45 / 45 /-45]_{\mathrm{s}}$} & 0.62979 & 0.6026453 & 4.31 \\
Stress $\left(\mathrm{S}_{\mathrm{xy}}\right):$ & {$[0 / 45 /-45 / 45 /-45 / 90 / 90 / 90]_{\mathrm{s}}$} & 0.18073 & 0.1851099 & 2.423 \\
\hline
\end{tabular}

\subsubsection{Numerical results for anti- symmetric laminated composite plate}

The linear layered structural shell element is used to analyse the anti-symmetric laminated composite plate for deflections and stresses. The material properties presented in Table 4 are utilized in this study. The plate is analysed with different fibre orientations. The non-dimensional deflections and non-dimensional stresses for symmetric and anti-symmetric laminated plates are presented in Table 6.

\begin{tabular}{lcccc}
\hline Fibre orientation & $\begin{array}{c}\text { Nondimensional } \\
\text { Deflection }\end{array}$ & $\begin{array}{c}\text { Nondimensonal } \\
\text { Normal stress } \\
\text { in X-direction }\end{array}$ & $\begin{array}{c}\text { Non-dimensional } \\
\text { Normal stress } \\
\text { in Y-direction }\end{array}$ & $\begin{array}{c}\text { Nondimensional } \\
\text { Transverse } \\
\text { shear stress }\end{array}$ \\
\hline$[0 / 90 / 0 / 90 / 0 / 90 / 0 / 90 /$ & 18.21264 & 0.88539 & 7.3502 & 0.3963 \\
$0 / 90 / 0 / 90 / 0 / 90 / 0 / 90]$ & 18.15792 & 7.5472 & 0.86512 & 0.33870 \\
{$[0 / 90 / 0 / 90 / 0 / 90 / 0 / 90]_{\mathrm{s}}$} & 3.286 & 3.0166 & 0.94943 \\
{$[45 /-45 / 45 /-45 / 45 /-45 / 45 /-45 /$} & 14.56388 & 2.9773 & 2.9887 & 2.6967 \\
$\begin{array}{l}45 /-45 / 45 /-45 / 45 /-45 / 45 /-45] \\
{[45 /-45 / 45 /-45 / 45 /-45 / 45 /-45]_{\mathrm{s}} 14.57604}\end{array}$ & & & \\
\hline
\end{tabular}

\section{Conclusions}

The two stage effort of obtaining the optimal stacking sequence by a new distance-based optimal design in design of experiments and artificial neural networks has resulted in fairly useful method for laminated composite plates. The following conclusions are drawn from the results for laminated composite material plates:

- The developed ANN model could predict the deflections and stresses $\left(\mathrm{S}_{\mathrm{x}}, \mathrm{S}_{\mathrm{y}}\right.$, and $\left.\mathrm{S}_{\mathrm{xy}}\right)$ with an average percentage deviation of $0.028875 \%, 1.587178 \%, 2.119705 \%$ and $3.018923 \%$ respectively from training data set.

- The ANN model could predict the deflections and stresses $\left(\mathrm{S}_{\mathrm{x}}, \mathrm{S}_{\mathrm{y}}\right.$, and $\left.\mathrm{S}_{\mathrm{xy}}\right)$ with an average percentage deviation of $6.132743 \%, 1.3096766 \%, 0.0945797 \%$ and $5.7492823 \%$ respectively from test data set.

- The ANN predicted results are very good agreement with the finite element results.

- For anti-symmetric laminated composite plates $[45 /-45]_{8}$, the non-dimensional deflection and transverse shear stress are lower compared to the symmetrical one.

- For anti-symmetric laminated composite plates $[0 / 90]_{8}$, the Normal stress in $\mathrm{x}$-direction is lower compared to the symmetrical one.

\section{Extensions and future studies}

The proposed distance- based optimal designs can be applied in structural analysis in determining the optimal set of laminates that requires practical stacking sequences for calculations because the new Distance-based optimal set of laminates provides optimal stacking sequences. The proposed Distance-based optimal design is not limited to 16-ply laminates. It is applicable to laminates of any number of plies by changing the ply thickness. The stacking sequence optimization can also be done using genetic algorithms; simulated annealing etc. the proposed design of experiments technique can also be applied to study the thermal, buckling and vibration behavior of laminated composite plates and shells.

\section{Nomenclature}

$\begin{array}{ll}D O E & \text { Design of Experiments } \\ F E & \text { Finite element } \\ A N N & \text { Artificial neural networks } \\ \text { UDL } & \text { Uniformly distributed load }\end{array}$




\begin{tabular}{|c|c|}
\hline$M L P$ & Multilayer perceptron \\
\hline$R$ & Coefficient of determination \\
\hline$N$ & In-plane force resultants \\
\hline$M$ & Moment resultants \\
\hline$A$ & Extensional stiffness matrix, relates in-plane forces to the in-plane strains \\
\hline$B$ & Coupling stiffness matrix, which couples the forces and moments to the mid-plane strain-curvature. \\
\hline$D$ & Bending moment stiffness matrix which relates bending moments to the plate curvature. \\
\hline$\varepsilon$ & Membrane strains \\
\hline$K$ & Curvature strains \\
\hline$T_{x}, T_{y}, T_{x y}$ & In-plane forces per unit length (output as TX, TY, and TXY) \\
\hline$M_{x}, M_{y}, M_{x y}$ & Bending moments per unit length (output as MX, MY, and MXY) \\
\hline$N_{x}, N_{y}$ & Transverse shear forces per unit length (output as NX and NY) \\
\hline$\sigma_{x}$. & Direct stress (output as SX) \\
\hline$\sigma_{x y}$ & Shear stress (output as SXY) \\
\hline$E_{1}$ & Young's modulus of the material in $\mathrm{X}_{1}$ direction \\
\hline$E_{2}$ & Young's modulus of the material in $\mathrm{X}_{2}$ direction \\
\hline$E_{3}$ & Young's modulus of the material in $\mathrm{X}_{3}$ direction \\
\hline$G_{12}$ & Shear moduli in $1-2$ plane \\
\hline$G_{13}$ & Shear moduli in 1-3 plane \\
\hline$G_{23}$ & Shear moduli in $2-3$ plane \\
\hline$v_{12}$ & Major poisson's ratio 1-2 plane \\
\hline$v_{13}$ & Major poisson's ratio 1-3 plane \\
\hline$v_{23}$ & Major poisson's ratio 2-3 plane \\
\hline$a$ & Length of the plate \\
\hline$b$ & Width of the plate \\
\hline$h$ & Thickness of the plate \\
\hline$q$ & Intensity of uniformly distributed load \\
\hline $\mathrm{w}$ & Deflection \\
\hline $\bar{w}$ & Non-dimensional displacement \\
\hline$\sigma_{x}\left(S_{x}\right)$ & Normal stress in $\mathrm{x}$-direction \\
\hline $\bar{\sigma}_{x}$ & Non-dimensional stress in $\mathrm{x}$-direction \\
\hline$\sigma_{y}\left(S_{y}\right)$ & Normal stress in Y-direction \\
\hline $\bar{\sigma}_{y}$ & Non-dimensional stress in Y-direction \\
\hline$\tau_{x y}\left(S_{x y}\right)$ & Shear stress in XY plane \\
\hline $\bar{\tau}_{x y}$ & Non-dimensional shear stress in XY plane \\
\hline$Q_{i j}$ & Reduced stiffness coefficients \\
\hline
\end{tabular}

\section{References}

Abouhamze, S. M. 2007. Multi-objective stacking sequence optimization of laminated cylindrical panels using a genetic algorithm and neural networks. Int. J. Composite Structures, Vol.81, No. 2, pp. 253-263.

Al-filfily A.A.H., 2011. Optimum design of composite laminated plate using genetic algorithm and RSM. J. Eng. \& Tech, Vol. 29, No. 5, pp.1-18.

ANSYS "Theory Manual" 2010.

Baker A., Dutton S. and Kelly D.. Composite Materials for Aircraft Structures $2^{\text {nd }}$ Edition. American Institute of Aeronautics and Astronautics, Inc.1801, Chapter 8, pp.240.

Choudhary S.S. and Tungikar V. B. 2011. A simple finite element for nonlinear analysis of composite plates. International Journal of Engineering Science and Technology, Vol. 3, No.6, 2011 pp.4897-4907.

Civalek O. 2008. Analysis of thick rectangular plates with symmetric cross-ply laminates. Journal of Composite Materials, Vol. 42, No. 26, pp. 2853-2867. 
Farshi B. and Herasati S..2005. Minimum weight design of fiber composite plates for bending. Iranian Journal of Mechanical Engineering, Vol. 6, No. 1, pp.18-37.

Haftka RT. and Walsh LJ..,1992. Stacking- sequence optimization for buckling of laminated plates by integer programming. AIAA $J$, Vol. 30, No. 3, pp. 814-819.

Han S.-C., Lee S.-Y.. and Rus G.. 2006. Postbukling analysis of laminated composite plates subjected to the combination of inplane shear, compression and lateral loading. International Journal of Solids and Structures, Vol. 43, pp. 5713-5735.

Kant. T., Marurb S.R. and Rae G.S.1998. Analytical solution to the dynamic analysis of laminated beams using higher order refined theory. Composite Structures, Vol. 40, No. 1, pp. 1-9.

Khoa N.N. and Thinh T.I. 2007. Finite Element Analysis of Laminated Composite Plates Using High Order Shear Deformation Theory. "Vietnam Journal of Mechanics", VAST, Vol. 29, No. 1, pp.47 - 57.

Kuzmanoviã M., Krèevinac S. and Vukmiroviã D.. 2005. The algorithms for constructing efficient experimental designs in conjoint analysis. The 7th Balkan Conference On Operational Research, Bacor 05, Constanta, May 2005, Romania, pp. 1-12.

Kuzmanovic M, Martic M., Vujosevic M. and Panic B.. 2011. Construction of efficient conjoint experimental designs using MCON procedure. International Journal of the Physical Sciences, Vol. 6, No. 24, pp. 5659-5670.

Le Riche R. and Haftka RT. 1995. Improved genetic algorithm for minimum thickness composite laminate design. Compos Eng; Vol. 5, No. 2, pp. 143-161.

Lin C.-C., Lee Y.-J., 2004. Stacking sequence optimization of laminated composite structures using genetic algorithm with local improvement. Int. J. Composite Structures, Vol. 63, No. 3-4, pp.339-345.

Marengo E. and Todeschini R. 1992. A new algorithm for optimal, distance-based experimental design, Chemometrics and Intelligent Laboratory Systems, Vol. 16, No. 1, pp. 37-44.

Meyers R.H. and Montgomery D.C.1995. Response Surface Methodology: Process and Product Optimization Using Designed Experiments, John Wiley \& Sons.

Montgomery D.C.., 2001. Design and analysis of Experiments, fifth ed., Wiley, New York.

Nguyen-Van H., Mai-Duy. and Tran-Cong T. 2007. Analysis of laminated composite plate/shell structures using a stabilized nodal- integrated quadrilateral element. $1^{\text {st }}$ International Conference on Modern Design, Construction and Maintenance of Structures, Hanoi, Vietnam, pp.1-8.

Pandya B.N. and Kant T. 1988. Finite element analysis of laminated composite plates using a higher-order displacement model, Journal. Composites Science and Technology. Vol.3, pp. 137-155.

Principe J., Lefebvre C., Lynn G.. Fancourt C.. and Wooten D.. Neurosolutions documentation available at http://www.neurosolutions.com/downloads/documentation.html.

Reddy J.N., 1997. Mechanics of Laminated Composite plates.CRC Press, Florida.

Riche R.L., Haftka R.T. 1993. Optimization of laminated stacking sequence for buckling load maximization by genetic algorithm. AIAA Journal, Vol.31, pp.951-956.

Shakeri,M.H., and Gol.M. 2007. Two objective stacking sequence optimization of a cylindrical shell using a genetic algorithm. $J$. Scientia Iranica, Vol.14, No. 5, pp.499-506.

Serpil Aktaş. 2011. Efficient Optimality Criterion for the Response Surface Designs. International Journal of Mathematics and Computation, Vol.13, No. D11, pp. 43-50.

Tahani A.M. and Naserian Nik.M. 2009. Bending Analysis of laminated composite plates with arbitrary boundary conditions, Journal of Solid Mechanics, Vol.1,, pp. 1-13.

Todoroki A, Terada Y. 2004. Improved fractal branch and bound method for stacking sequence optimizations of laminated composite stiffener. AIAA Journal, Vol.42, No. 1, pp.141-148.

Todoroki A. and Ishikawa T. 2004. Design of experiments for stacking sequence optimizations with genetic algorithm using response surface approximation. Int. J. Composite Structures, Vol. 64, pp. 349-357.

Todoroki A.. and Sasai M. 2003. Stacking sequence optimizations using GA with zoomed response surface on lamination parameters. Adv. J. Composite Mater., Vol. 11, No. 3, pp. 299 - 318.

Todoroki A. and Sekishiro M. 2007. New iteration fractal branch and bound method for stacking sequence optimizations of multiple laminates. J. Composite Structures, Vol.81, pp.419-426.

Yuarrming X.U., Shuo L.L. and Xiao-Min R. 2005. Composite structural optimization by genetic algorithm and neural network response surface modeling. Chinese Journal of Aeronautics, Vol. 18, No.4, pp. 310-316.

\section{Biographical notes}

Mr. A. Ramanjaneya Reddy is graduated in 2009, from R.G.M. College of Engineering, Nandyal. He is pursuing master's degree from R.G.M College of Engineering, Nandyal in machine design. His areas of interests are composite materials, alternative fuels, optimization techniques and soft computing.

Mr.B.Sidda Reddy, obtained his Masters Degree from S.V University, Tirupati in 2007.He is working as Assistant Professor in the Department of Mechanical Engineering in R.G.M College of Engg. \& Tech.Nandyal, Andhra Pradesh Since 2005.He has presented 09 papers in National and International Conferences, 07 papers has published in National Journal and 15 papers has published in International Journal. His areas of interests are I.C Engines, Alternative fuels \& CFD, Optimization techniques, soft computing, composite materials. 
Dr. K. Vijaya Kumar Reddy, is graduated in 1988, Masters in 1992 and did his Ph.D from JNTU College of Engg., Anantapur in 2000. He guided three Ph.D students and another $16 \mathrm{Ph}$. D scholars doing their research under his guidance. He has presented and published more than 100 papers in Various National \& International Conferences. He has organized 7 national level conferences \& short term courses and attended 6 National workshops during past 6 years. He had supervised the following important activities at JNTUCE, Anantapur such as NSS Programme officer, Deputy Warden, Officer in charge of hostels, Student Union coordinator, Alumni Association Secretary cum Treasurer, Officer in charge of Academic section. At Present, he is working as Professor of Mechanical Engineering at Jawaharlal Nehru Technological University, Hyderabad

Received November 2011

Accepted January 2012

Final acceptance in revised form February 2012 